\title{
Carl Jung's Archetypes in Malayalam Film: A Case Study on The Film 'Urumi'
}

\author{
Sona Varghese ${ }^{1, *}$ and Arumugam Balasubramanian ${ }^{2}$ \\ 1,2 Department of Communication, Coimbatore, Amrita Vishwa Vidyapeetham University, Tamil \\ Nadu, India
}

\begin{abstract}
Movies are the visual- auditory symbolic narrative that explains the living reality of people. Films employ Carl Jung's concept of archetypes-prototypical characters. This research provides an insight about the theory of archetype based on the assumption that archetypes resides deep inside human mind. The researcher proposes that the Malayalam film industry in India showcases the western concept of archetype using the movie Urumi as a case study. For this study, different clips are taken from the movie to represent six essential archetypes, namely, Hero, Anima, Animus, Mentor (sage), Shadow, and Trickster. The psychoanalysis of this movie carried out in this paper provides evidence for the existence of all six essential archetypes identified by Carl Jung. Thus this article will be a fruitful resource for future research in the field of psychoanalysis of movies.
\end{abstract}

\section{Introduction}

The mass media has gone through various development and refinement in past centuries. The contemporary information age is dominated by mass communication media such as movies, television and internet [1]. The stories and characters presented in this mass media are important for sharing human experience. People use movie plot analogies and metaphors in their life due to its effect on the mass audience [6]. The phenomena of using the examples of movies and other mass media in ordinary life, points to the existing internal psychological forces that allows people to connect with these commonly shared metaphors and analogies.

The shared cultural phenomenon which unites people in a thread is the archetype. The concept of archetypes is taken from collective unconsciousness, a theory developed by the Psychologist Carl Gustav Jung. In collective unconsciousness, Jung suggest that, all human beings share a deep level of unconscious mind universally which is hidden beneath the personal psyche [16]. The collective unconsciousness contains modes of behavior and some contents which are identical in every human being that include a common psychic content of a universal nature present in individuals across the globe. Thus, human beings shows a tendency to perceive common meanings embodied in a particular symbol as same, even at the unconscious level [2].

* Corresponding author: a_balasubramanian@cb.amrita.edu 
Jung developed the concept of archetypes in 1964. Archetypes were defined as the components of collective unconsciousness which is an inborn tendency acquired in the unconscious mind. They exist in psych and prepare individuals to deal with life experiences psychologically that are common for everyone [22]. An extreme analogy of describing archetypes will be as the structure of psyche, which is similar to organs inside physical body [13].

Archetypes are represented as ancient motifs and preconceptions about the behavioral patterns that are symbolically manifested as archetypes in all cultural forms, arts and in dreams. Jung formulated and identified archetypes from his patients and from his own emotions by verbalizing the visualized images for certain concepts [16]. Drawing Mandala archetype symbol from Hinduism helped Jung to represent 'The self'. Mandala is also considered as a telematic design of cosmos and consciousness which represents high spirituality among humans [11]. The other archetypes include, Anima, Animus, Sage and Mother, and they have been identified as the major elements in the common language which involves the stories people communicate with others [6], [18]. Archetypal characters assert certain characteristic motives and other qualities to promote actions that everyone can recognize.

In modern day media, these archetypal figures take form through visual narratives. Movies are the visual- auditory symbolic narrative that explains the living reality of people [4]. Based on Jung's theory, movies have become a resource for studying archetypes in popular culture and contemporary society. Cinema offers the content and also the means for psychotherapeutic sessions which enables the viewer to identify their psyche with the projection in screen. The cinema also claims to be a platform in the contemporary society where people can set apart from their daily life and connect with their unconsciousness similar to a session of hypnosis or dreaming [9].

A number of studies have proposed and proved the presence of archetypes in the stories of various cultures [14]. The archetypal analysis on movies has been conducted in the western film industries to have an insight on the psychoanalysis of movies. The studies include archetypal analysis of Jim Casey in the Grapes of wrath. In the analysis the author has compared Jim Casey with Christ. The Christ is considered as a leader, forerunner and a sacrificial figure who sacrifices his life for cleansing the sins of others and was in a constant battle with the Satan [7]. The other study is on the famous adventurous movie series Indiana Jones. The heroic myth by Joseph Campbell is influenced by the archetypal situation of Jung. This was later shortened by Christopher Vogler and is present in Indiana Jones than in any other movies. In the movie, Indiana Jones; Raiders of Lost Ark', the first stage called ordinary world is established through showing the life of Jones as a college professor [5].

The movies across the globe have some universal characteristics especially in the context of psychology and therefore can be applied in the Malayalam film industry in India. The study focuses on conducting psychoanalysis of Malayalam movie Urumi based on Carl Jung's Archetypes and monomyth.

\section{Urumi}

Urumi is the Malayalam movie filmed, directed and co-produced by Santhosh Sivan. The movie is the recent release in the genre, Indian epic historical drama of Malayalam film Industry. The film is an adoption from the real life of a patriotic warrior Kelu Nayanar in $16^{\text {th }}$ century whose father was killed by the explorer Vasco da Gama and his troops. The movie is set on two different centuries, the contemporary $21^{\text {st }}$ century and $16^{\text {th }}$ century. The main characters and their mirror reflections along with similar situations connect one era to the other. The story mainly focuses and narrates the journey of Kelu Nayanar (Prithviraj) 
and his journey to avenge the death of his father and to redeem the freedom of Indians fromVasco, who have taken the authorization of Indian Ocean and his motherland. He is accompanied by his friend Vavali (Prabhu Deva) and a warrior princess Ayesha of Arakkal (Genelia D'souza). The story set in $16^{\text {th }}$ century is connected to the contemporary world through the predecessor of Kelu Nayannar and his mirror reflection Krishna Das in the $21^{\text {st }}$ century.

\section{Objectives}

The researcher through this study aims to identify and analyze portrayal of Carl Jung's six archetypes in the Malayalam film Urumi.

\section{Analysis and Interpretation}

Table 1. Archetypes character identified in the movie

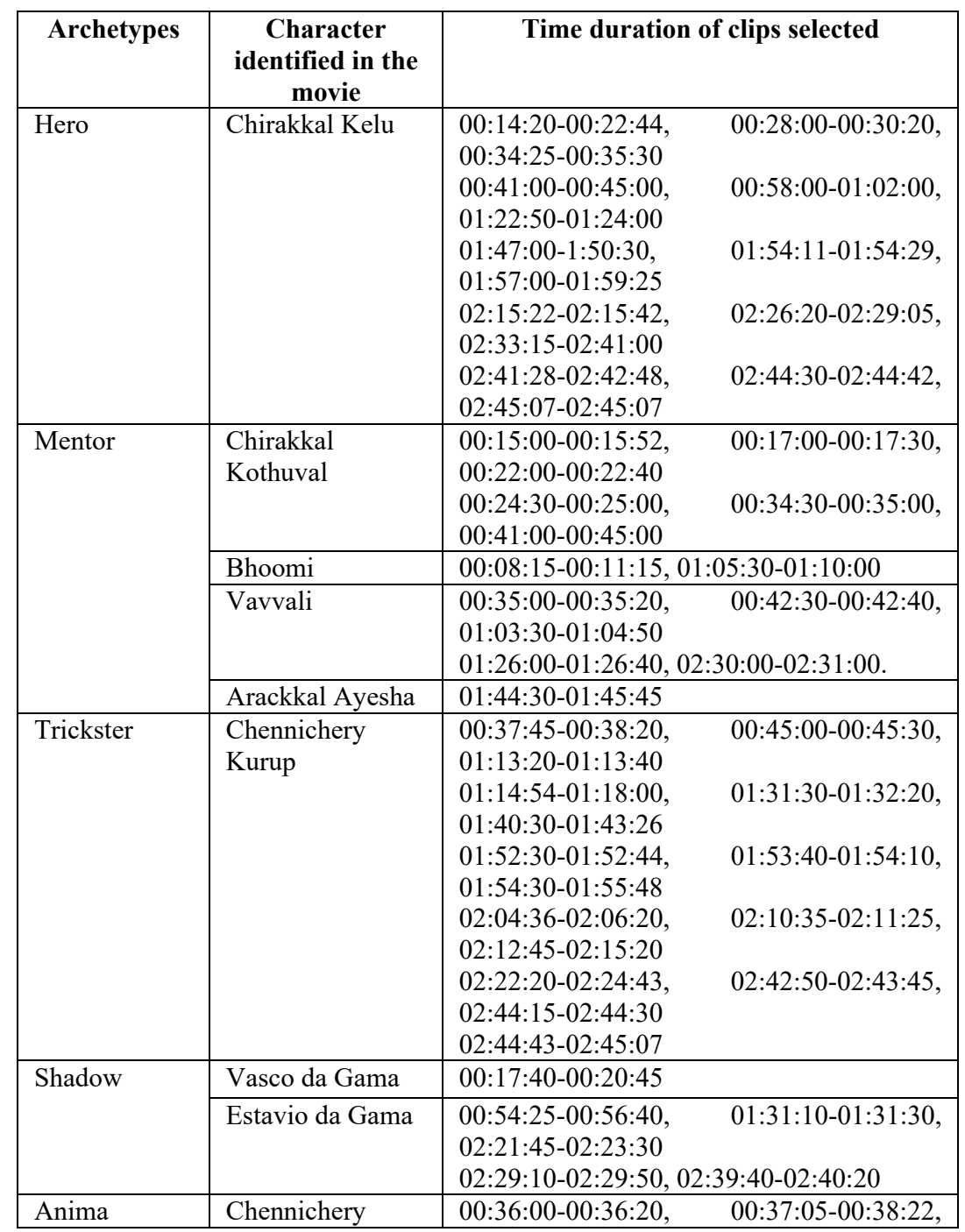




\begin{tabular}{|l|l|ll|}
\hline & Kurup & $01: 11: 10-01: 12: 30$ & \\
& & $02: 13: 00-02: 15: 00,02: 22: 20-02: 24: 20$ \\
\hline Animus & Arackkal Ayesha & $00: 50: 30-00: 53: 25$, & $00: 57: 30-00: 58: 23$, \\
& & $00: 58: 55-01: 00: 10$ & \\
& & $01: 20: 55-01: 22: 00$, & $01: 24: 00-01: 24: 15$, \\
& & $01: 26: 45-01: 27: 50$ & \\
& & $01: 33: 15-01: 35: 21$, & $01: 43: 34-01: 45: 45$, \\
& & $01: 49: 35-01: 50: 10$ & \\
& & $01: 53: 21-01: 53: 36$, & $01: 57: 08-01: 59: 15$, \\
& & $02: 18: 40-02: 20: 20$ & \\
\hline
\end{tabular}

The table 1 shows the collection of clips of each character, under the six archetypes based on which we conducted the analysis. The hero, mentor, trickster, shadow, anima and animus are identified and the clips are taken based on the definitions given by Jung. The analysis is based on each clip mentioned in this table with supporting statements of definitions.

\subsection{Hero}

The word hero has connotations with adversity, challenges, honour, strength and victory [3]. It is the duty or responsibility of the hero to make the wrong things right and make his world into a utopian paradise. Kelu Nayannar (Krishna Das in mundane world) is the hero archetype identified in the movie Urumi. The Hero archetype has an alluring character since childhood. He has to contend with forces that would deny him his own independence and self-direction [12]. In the first part at magical world, Kelu Nayannar's childhood is shown when Vasco Da Gama arrives with warships to attack Kerala. In this part the situations which change the entire life of Kelu and make him an orphan is portrayed keeping his father Chirakkal Kothuval as the central figure and an ideal for his son Kelu. The cruelty imposed by Gama and the murder of his father shakes his roots and force him to give over his independence and direction of life. Thus he develops contend for Gama and his troops which took his independent life and father. Kelu grows up to avenge for the death of his father and to redeem his and his motherland's freedom from whites.

The hero is faced with some countless struggles for the remainder of his life which involve the epic life and death proportions [12]. Kelu after getting rescued by his father is left alone in the sea banks where he sees the scattered dead bodies of his loved ones. He stands in between the proportions of life and death on the seashore with the gold gifted by a dying mother. Later the young orphan Kelu makes his life with his friend Vavali and turns the gold into a magical weapon, a golden Urumi (whip sword). He receives education from different places and learns about war tactics, weapons and literature. This is shown in the scene where Kelu has a talk with Chirakkal King. These situations acted like a constant guide light for the hero.

The warrior modality in the hero is so strong that slaying others is considered a necessity for protecting himself and the things he value. The outcome of each fight is not just the victory over evil but it also shows how personal convictions can shape the world for a better tomorrow if people take charge of their life [19]. Kelu is a warrior from the moment he is shown in the $16^{\text {th }}$ century. His warrior capability is established when he saves the Chirakkal princess Bala from the attackers. Later his warrior capabilities can be seen when he kills and attacks the Portuguese troops arrived to convict Arackkal Baliyahasanan at Arackkal fort. He also rescues Ayesha from Chirakkal guards and then rescues other women of Arackkal from the jail. Throughout the movie we get various other instances when Kelu is shown slaying the enemies with his Golden Urumi. It includes the battles with Portuguese army men who comes to rescue Estavio, and also with Estavio himself and his 
troops. In the climax Kelu dies in such a battle but only to resurrect inside the hearts of people and also inside Krishna Das, Kelu's mirror image and predecessor in the mundane world. It is from the wisdom gained from the mentors and Kelu's story that opens the insight of Krishna Das and forces him to sacrifice everything for the people living in his ancestral property. Thus the hero becomes the master of both the magical and mundane world.

\subsection{Mentor}

The immature hero needs counseling to face the adventures and tests in the journey for quest. This is where the mentor archetype comes into scenario. The mentor archetype exemplifies the hidden strength which the hero needs to carry out through the journey. The mentor may not always live in the main stream society but in a secret abode like a hermit [16]. In the movie there are two main mentors and two side kick mentors. The main mentor is Chirakkal Kothuval( Hero's father in magical world)/ Thankachan (The tribal head in mundane world) played by actor Arya. The other important mentor is Bhoomi, the NGO head in mundane world and a nameless mythical magician in magical world. The sidekick mentors are Vavali and Arackkal Ayesha.

Thankachan is the mirror reflection of Chirakkal Kothuval in the $16^{\text {th }}$ century. The mentor (sage) through his wisdom and moral insight is able to induce the self reflection in hero. Who am I? Where am I? What is the purpose of my journey? -These are the questions posed by the mentor to make the hero stop and think before action [15]. In the first part of the movie where hero confronts Thankachan, the tribal head informs Krishna das about his royal lineage and about the ancestor Kelu Nayannar who fought for the motherland and father in the soil which Krishna das intend to sell. Thankachan narrates the story of Kelu to Krishna Das to make him understand the importance and value of the soil which he wants to sell for money.

Krishna das is the mirror reflection of Kelu in the mundane world. The real mentor image of Thankachan comes in the magical world as Chirakkal Kothuval. The mentor archetype can also be compared to that of a father archetype because they act as a role model for the hero. The father-mentor archetype is often pictured as a strong and powerful leader. Sometimes he disciplines his subjects with a benevolent hand and at other instants he will enforce power with iron fists [17]. Chirakkal Kothuval, the knight at Chirakkal kingdom is the protector of people under his realm. He is also seen as the teacher and guide for his son and other soldiers under the Chirakkal Kingdom in the first part of movie. He enforces his power against Vasco da Gama and his Portuguese army men who tries to attack his land. Even after his death, Kelu is always guided by the knowledge and wisdom passed to him through his father. When hero returns to the mundane world, Thanachan provides the magical weapon, the golden Urumi to Krishna Das who undergoes purgation through the story of Kelu. This aspect of mentor providing a magical weapon to hero according to Jung's mentor archetype is the final feather to the main mentor character in the movie.

The mentor Bhoomi is the mirror reflection of the mystical women in the magical world who comes as a prophet into the journey of Kelu and Vavali. In first part, she comes as a social worker who is currently taking care of the NGO started by late Chandramani Thampuratti, the mother of Krishna Das. Bhoomi tries to tell Krishna das about the social issue related to the sale of his ancestral property but fails in the beginning. She presents him the pen used by his mother as emotional magical weapon which might help the hero to stay for a moment and think. This connects to the characteristics of mentor character who leads the hero to stop and think before action. The main role of Bhoomi lies in the mystical oracle character in the $16^{\text {th }}$ century. 
Kelu after capturing Estavio Da Gama is in confusion whether or not to kill Estavio and also about going back to Chirakkal. The mystical character of Bhoomi arrives as a mentor at that time. Sleeping on the problem is as important as engaging in the warrior mode, when combined both qualities together, it will ensure the hero's success in the battle [17]. The mystical character comes to provide a sleeping time for hero as the hero and his loyal retainer sleeps while listening to the oracle both in symbolic and practical aspect. The mentor posses' great magical abilities often referred to as a magician can communicate ideas and suggestions through dreams [17]. The mystical character announces the prophecy that Kelu will first become the knight of Chirakkal and later King. The magical mentor also asks them to be brave and go through the way lighten by the light inside the heart through the song. After the song sequence, the hero and his loyal retainer get into the confusion whether it was a dream or reality. The sidekick mentor Vavali guides Kelu when he loses his path by providing wisdom to him. Ayesha on the other hand can be seen as a mentor when she suggests Kelu to create troops from villages for an army to fight against Gama. Because fighting alone against Portuguese would have been foolish. The mentor can only show the way to hero and cannot force him to take the way. Fortunately in all stories hero listens to the mentor and acts according to the suggestions given by the mentor [4].

\subsection{Trickster}

The medieval description of devil is considered as an ape of God 'Simia dei' and his characterisation in folklore is that of a simpleton who is a cheater and trickster. The trickster is known for his fondness towards sly jokes, malicious pranks, dual nature and his exposure to all kinds of torture which makes him a negative figure [15]. In this movie, Minister of Chirakkal, Chennichery Kurup is recognized as the trickster. Chennichery is the ape of God in the movie who is a cheater and a trickster. In the first introductive narration given for Chennichery narrates how he is the only minister who escaped from the Ministers held as captives under Gama. In the description of trickster given by Jung, he states that the trickster must have gone through tortures which makes him wicked and leads to spread destruction around him. He also shows the characteristics of a homosexual which indicates the duality of nature. Chennichery kurup is seen to have a fond of sly jokes and malicious pranks throughout the movie.

The trickster tempts to attack hero with his sly jokes and pranks on hero [15]. In the scene where Prince Bhanu Vikraman brings Kelu and Vavali as the ones who tried to kill his sister, Chennichery is first seen as saying sly jokes at Kelu. It is even carried out when Kelu and Vavali are served food at Chennichery's residence after declared innocents by Chirakkal princess Bala. In the following scene where Arrackal women are brought in front of the Chirakkal King, Chennicheri follows similar sly jokes. Chennichery is also seen playing malicious pranks and shows a hidden support towards the Portuguese and Gama. Tricksters may be sentiments or allies working for the shadow or they may be independent agents with their own skewed agendas [15]. Chennichery, in the first scene of him shows a hidden support and slant towards Gama. He educates the Chirakkal King about the profit Portuguese can provide in return of Pepper and Black gold of Kerala. Trickster Kurup even tries to kill the hero who is sent to capture Gama arriving in Arackkal by Chirakkal King. The minister is also seen as taking care of the son of Vasco Da Gama, Estavio Da Gama. He even tricks the Chirakkal prince Bhanu to support Gama in return of showing the final victory, the throne of Chirakkal. The trickster Kurup is sole shadow who makes a son to kill his father. Thus Bhanu kills the Chirakkal King with the support of Kurup.

Trickster is seen as the personification of chaos and mischief for its own sake [3]. Chennichery destroys the Chirakkal kingdom for the ownership of Lakshadweep Islands offered by Gama. This gets revealed only towards the Climax of the movie when Kelu 
confronts Chennichery after the death of Chirakkal King. In this scene we also see the shaman in Kurup. Trickster from medieval period is considered to practice Shamanism [15]. Kurup is shown applying black medicine in beetle leaves which is fed to King when the King gets out of the influence of Kurup. But the intention behind the black medicine is understood when in the climax Kelu confronts Kurup. Thus all these facts prove Chennichery to be a trickster and it becomes evident when at last Kurup watches Prince Bhanu getting killed by Estavio and makes Kurup the governor of Lakshadweep.

\subsection{Shadow}

The shadow archetype is the opposite of light and provides the tension, anxiety and fear in the story. The shadow is often seen opposing the hero and typically the main antagonist [21]. The movie Urumi has two shadow figures, Vasco da Gama and his son Estavio Da Gama. The shadow operates in the prelogical thoughts governed by strong desires and animalistic needs [10]. In the movie, the first part when Gama returns to Kerala with war ships provides evidence for Gama's prelogical thought process to have a war with Samoodri and Kolathiris, the main Kingdoms in Kozhikode, Kerala. His strong desire towards the black gold, pepper became an obsession for Gama and his troops. For attaining the desire Gama left his humanity. His animalistic characteristic can be seen when the Brahmin mediator approaches Gama with the child Kelu in the ship. Gama creates a scar on the face of Kelu for looking straight into Gama's eyes. He is also seen cutting the tongue and chopping down the ear of Brahmin mediator. Later Gama stitches the ear of Gama's dog to the mediator. Here we can see the face of shadow figure who teaches discipline to the people who come as an obstacle in his line of attack.

Estavio Da Gama is also seen as the shadow figure, like his father. It is visible when Estavio arrives at Arackkal fort to crucify Baliyahasan. Estavio brutally injures the rebel captured for fighting against Portuguese with Baliyahasanan and also hurts Baliyahasan by trying to pull of his ears and hair. Estavio even takes revenge to Vavali by shooting him down to trap him at Chirakkal as a cover for rescue held by Kelu to save Arackkal women captives. Towards the end it is Estavio who leads to the death of Kelu Nayannar by shooting the hero from back. The shadow figures are often seen as breaking the rules and norms set by society for their personal needs.

\subsection{Anima}

Anima is an archetype based on gender. In the unconscious of the male, the archetype anima is the feminine inner personality where as animus is expressed as the masculine inner personality in the unconscious of female. The anima is the most important factor in the psychology of man for emotions and its affects [16]. In this movie the character of Jagathi Sreekumar as the Minister of Chirakkal Chennichery Kurup is identified as the archetype anima. The anima intensifies and exaggerates the soft but sharp emotions to generate fantasies and entanglements [16]. In the movie Chennichery enacts the role as a homosexual. The character dressed up partially like a woman shows the characteristics of a woman. The mannerism adopted by Chennichery clearly indicates towards his inner feminine overpowering the masculine. The character intensifies the jealousy and insecurities of Prince Bhanu Vikraman and exaggerates the emotions of Chirakkal King and Prince to fulfill his own fantasies. For that he creates entanglements around the King and Prince.

According to Jung, when anima is strongly constellated, it softens the character of a man and makes him touchy, irritable, jealous and moody with vain. $\mathrm{He}$ is then in a discontent state and spreads discontent all around him [16]. Chennicherry displays the 
irritation and jealousy when Kelu Nayanar and Vavali get importance in the Chirakkal kingdom over him. The aftermath of this is visible when he tries to talk to Chirakkal king about them. The mood variations and his vain over Kelu and Vavali can also be seen in the way Chennichery nicknamed them based on their caste as Nayanar (Nair) to Kelu and Mohammaden (Muslim) to Vavali. The anima characteristic of Chennichery overrules him and associates him to greedy and jealous women. Kelu's confrontation scene with Chenichery after Chirakkal King's death provides a proof for this. The moody jealous and irritated Kurup later is seen as a negative figure that spreads discontent all around him by doing treachery against his own motherland for his personal needs.

\subsection{Animus}

In the female unconscious, she is compensated by a masculine element and therefore has a masculine imprint which is called as animus. Animus is the counterpart of anima in the psyche of female. This influences woman's interaction and attitude towards men. The woman will attain masculine characteristics like stubbornness, lust for power, chivalry and willfulness [15]. The movie Urumi, has an animus archetype in the character of Princess of Arackkal, Ayesha. She exhibits strong masculine qualities like that of a warrior who killed the people who tried to attack her and her family. In the narrative part of Ayesha's introduction, the author narrates that the stubbornness displayed by the princess is the reason for her abduction by Portuguese army men. Arackkal Ayesha is also one among the rivals fighting for freedom even after strong oppositions from her own family. It shows her willfulness and commitment towards her motherland.

The overwhelming demeanor and always right attitude can test the limits of the patience of a man to the part where he drives unstable because of this incredibly strong Animus [8]. The overwhelming demeanor of Ayesha can be seen the way she first reacts to Kelu. She blames him for the cruelty happened to her baby sister by the Prince of Chirakkal in the Chirakkal Kingdom. Kelu saves them and takes the female captives of Arackkal to a safe zone; even then she refuses to show the sign of any gratitude or apology for her behavior. In the scenes followed Kelu gives up in front of her attitude and allows her to do according to her wish. The Ayesha later when the movie attains syzygy by accepting her both anima and animus when she falls in love with Kelu and therefore avoids any discontent.

\section{Conclusion}

Carl Jung's archetypes have been subject for study by many researchers, mostly due to its universality. The researchers from west proved that archetypes, globally accepted symbols and its interpretations are widely used in mass media. The movie Urumi is one of the latest releases in the Indian historical epic genre of Malayalam film industry in India. The psychoanalysis of this movie carried out in this paper provides evidence for the existence of all six essential archetypes identified by Carl Jung. Thus this article will be a fruitful resource for future research in the field of psychoanalysis of movies.

\section{References}

1. $\quad$ L.Bogart, Med. Stu. J, 5, 13-33 (1991)

2. S.Bradshaw, L. Storm, Int. J. of Jun. Stu (2013)

3. J. Campbell, The hero with a thousand faces (Princeton, N.J.: Princeton University Press. (2013)

4. H.M. Chang, L.Ivonin,M. Diaz, A J. of Spe. Res..11, 99-113 (2013) 
5. R.Crespolini, Indian Jones Master Thesis (2002)

6. C.Downing, Mirrors of the self: Archetypal images that shape your life. Los Angeles: Jeremy P. Tarcher. (1991)

7. Y.Fan, TPLS. 4 (2014)

8. F.Fordham, An introduction to Jung's psychology. Harmondsworth: Penguin books. (1966)

9. C.Hauke,I. Alister, Jung and film: Post Jungian takes on the moving Image. East Sussex, UK: Brunner- Routledge. (2001)

10. R.Hopcke, A Guided Tour of the Collected Works of C.G. Jung. Boston: Shambhala. (1999)

11. J.A.Huh, TA: A J. of Spe. R (2010)

12. J.Iaccino, Jungian reflections within the cinema a psychological analysis of sci-fi and fantasy archetypes. Westport, Conn.: Praeger. (1998)

13. J.Jacobi, The psychology of C.G Jung. London, Uk: Yale University. (1973)

14. L.Jadot. Rev. Psy. Edu., 10, 367-374 (1975)

15. C.G Jung,Jung and archetypes, The collected works of C.G Jung. Princeton, N.J.: Princeton University Press. (1968)

16. C.G.Jung, The archetypes and collective Unconscious. Princeton, NJ:Princeton University Press. (1981)

17. C.G. Jung, Memories, dreams, reflections. New York, NY:Vintage. (1989)

18. M. Mark, C. S.Pearson, The hero and the outlaw: Building extraordinary brands through the power of archetypes. New York: McGraw Hill. (2001)

19. C.S. Pearson, The hero within: Six archetypes we live by San Francisco: Harper \& Row. (1989)

20. C.S.Pearson,H.K .Marr, Pearson-Marr Archetype Indicator. Gainesville,FL: Center for Applications of Psychological Type. ( 2001)

21. .C. Vogler, M.Montez, The writer's journey: Mythic structure for writers. Studio City, CA: Michael Wiese Productions. ( 2007)

22. S.Walters, J. Soc. Evo. Sys 17, 287-306 (1994) 